\title{
Draft genome of a novel methanotrophic Methylobacter sp. from the volcanic soils of Pantelleria Island
}

\author{
Carmen Hogendoorn • Nunzia Picone - Femke van Hout - Sophie Vijverberg • \\ Lianna Poghosyan (i) - Theo A. van Alen • Jeroen Frank (D) Arjan Pol • \\ Antonia L. Gagliano (i) - Mike S. M. Jetten (D) Walter D'Alessandro (D) \\ Paola Quatrini (1) Huub J. M. Op den Camp 1
}

Received: 26 November 2020/ Accepted: 22 January 2021 / Published online: 10 February 2021

(C) The Author(s) 2021

\begin{abstract}
The genus Methylobacter is considered an important and often dominant group of aerobic methane-oxidizing bacteria in many oxic ecosystems, where members of this genus contribute to the reduction of $\mathrm{CH}_{4}$ emissions. Metagenomic studies of the upper oxic layers of geothermal soils of the Favara Grande, Pantelleria, Italy, revealed the presence of various methane-oxidizing bacteria, and resulted in a near complete metagenome assembled genome (MAG) of an aerobic methanotroph, which was classified as a Methylobacter species. In this study, the Methylobacter sp. B2 MAG was used to
\end{abstract}

Supplementary Information The online version contains supplementary material available at https://doi.org/10.1007/ s10482-021-01525-7.

C. Hogendoorn · N. Picone · F. van Hout .

S. Vijverberg · L. Poghosyan · T. A. van Alen ·

J. Frank · A. Pol - M. S. M. Jetten .

H. J. M. Op den Camp ( $\square)$

Department of Microbiology, IWWR, Radboud

University, Heyendaalseweg 135, 6525 AJ Nijmegen, The

Netherlands

e-mail: h.opdencamp@science.ru.nl

A. L. Gagliano · W. D’Alessandro

Istituto Nazionale di Geofisica e Vulcanologia, Sezione di Palerma, Via U. La Malfa 153, 90146 Palermo, Italy

P. Quatrini

Department of Biological, Chemical and Pharmaceutical Sciences and Technologies (STEBICEF), University of

Palermo, Viale delle Scienze Ed. 16, 90128 Palermo, Italy investigate its metabolic potential and phylogenetic affiliation. The MAG has a size of 4,086,539 bp, consists of 134 contigs and 3955 genes were found, of which 3902 were protein coding genes. All genes for $\mathrm{CH}_{4}$ oxidation to $\mathrm{CO}_{2}$ were detected, including pmoCAB encoding particulate methane monooxygenase (pMMO) and $x o x F$ encoding a methanol dehydrogenase. No gene encoding a formaldehyde dehydrogenase was present and the formaldehyde to formate conversion follows the tetrahydromethanopterin $\left(\mathrm{H}_{4} \mathrm{MPT}\right)$ pathway. " $\mathrm{Ca}$. Methylobacter favarea" B2 uses the Ribulose-MonoPhosphate (RuMP) pathway for carbon fixation. Analysis of the MAG indicates that $\mathrm{Na}^{+} / \mathrm{H}^{+}$antiporters and the urease system might be important in the maintenance of $\mathrm{pH}$ homeostasis of this strain to cope with acidic conditions. So far, thermoacidophilic Methylobacter species have not been isolated, however this study indicates that members of the genus Methylobacter can be found in distinct ecosystems and their presence is not restricted to freshwater or marine sediments.

Keywords Methane - Methanotroph · Volcanic soil · Metabolic potential 


\section{Introduction}

Volcanic and geothermal areas are hostile environments characterized by low $\mathrm{pH}$, high temperature, geothermal gas emissions, and low $\mathrm{O}_{2}$ concentrations. One of the emitted geothermal gases is $\mathrm{CH}_{4}$, a potent greenhouse gas. Multiple studies have shown that aerobic methanotrophs may be important in reducing the emissions of geothermally produced $\mathrm{CH}_{4}$ (D'Alessandro et al. 2009; Etiope and Klusman 2002).

Phylogenetically, aerobic methanotrophs belong to the phyla Alphaproteobacteria, Gammaproteobacteria or Verrucomicrobia (Op den Camp et al. 2009). These methanotrophs are microorganisms that conserve energy by oxidizing $\mathrm{CH}_{4}$ to $\mathrm{CO}_{2}$, while using $\mathrm{O}_{2}$ as terminal electron acceptor (Hanson and Hanson 1996). The first step of the methane oxidation pathway involves the conversion of methane into methanol catalysed by a soluble or membrane-bound methane monooxygenase (Hanson and Hanson 1996). In the following steps, methanol is converted into $\mathrm{CO}_{2}$ via formaldehyde and formate using either lanthanidedependent XoxF-type methanol dehydrogenase or a calcium-dependent MxaF-type methanol dehydrogenase (Keltjens et al. 2014). Carbon fixation occurs via the Ribulose-Mono-Phosphate (RuMP) pathway, the Serine Pathway or the Calvin-Benson-Bassham (CBB) cycle (Chistoserdova 2011; Khadem et al. 2011; Murrell 1992; Rasigraf et al. 2014; Sharp et al. 2014).

Previous studies using analysis of 16S rRNA genes or the diagnostic pmoA gene revealed the presence of methanotrophs in volcanic areas (Gagliano et al. 2014, 2016; Niemann et al. 2006). Thermoacidophilic methanotrophs from geothermal areas have been isolated and resulted in the first pure cultures of methanotrophic members of the phylum Verrucomicrobia (Dunfield et al. 2007; Erikstad et al. 2019; Islam et al. 2008; Pol et al. 2007; van Teeseling et al. 2014).

A recent metagenomic analysis of the volcanic soils of the Favara Grande, the main geothermal active area of Pantelleria Island, Italy, indicated the presence of a unique methanotrophic community, composed of Verrucomicrobia and Gammaproteobacteria (Picone et al. 2020). Different metagenome assembled genomes (MAGs) were retrieved. One of these MAGs was nearly complete and phylogenetic analysis showed that it represents the genome of a novel Methylobacter species. Typically, Methylobacter species are found in freshwater sediments and wetland soils, where they account for a large fraction of aerobic methanotrophs (Smith et al. 2018). Thermoacidophilic Methylobacter species have, so far, not been isolated. In this study, we determined the phylogenetic position of this Methylobacter, and analysed the encoded metabolic potential.

\section{Materials and methods}

Sampling location and DNA isolation

Samples were collected at Favara Grande, Pantelleria, Italy 2017 (FAV1, 36 50 80 $0^{\prime \prime} \mathrm{N} ; 11^{\circ} 57^{\prime} 170^{\prime \prime} \mathrm{E}$ ) and (FAV2, 36 $50^{\prime} 77^{\prime \prime} \mathrm{N}$; $11^{\circ} 57^{\prime} 160^{\prime \prime} \mathrm{E}$ ) during a field campaign in June 2017 (Picone et al. 2020). Soil samples (1-10, 10-15 and 12-20 cm depth) were taken using a core sampler (diameter $1.5 \mathrm{~cm}$ ), stored in sterile $50 \mathrm{~mL}$ tubes and kept at $4{ }^{\circ} \mathrm{C}$ until DNA was extracted. In situ $\mathrm{pH}$ values were 4-4.5 with temperatures from 60 to $67^{\circ} \mathrm{C}$. Two different DNA extraction methods were used, namely Fast DNA Spin kit for soil (MP Biomedicals, Santa Ana, California), according to manufacturer's instructions, and the CTAB method (Allen et al. 2006). DNA extraction was only successful from the FAV2 sampling site and the reads from the different depths and different extraction methods were combined for assembly and binning. For more detail see Picone et al. (2020).

Genome sequencing, assembly and binning

The metagenome was sequenced on the Illumina sequencing platform. For library preparation the Nextera XT kit (Illumina, San Diego, California) was used according to the manufacturer's instructions. Enzymatic tagmentation was performed starting with $1 \mathrm{ng}$ of DNA, followed by incorporation of the indexed adapters and amplification of the library. After purification of the amplified library using AMPure XP beads (Beckman Coulter, Indianapolis), libraries were checked for quality and size distribution using the Agilent 2100 Bioanalyzer and the High sensitivity DNA kit. Quantitation of the library was performed by Qubit using the Qubit dsDNA HS Assay Kit (Thermo Fisher Scientific, Waltham, Massachusetts). The libraries were pooled, denatured and sequenced with the Illumina Miseq sequence machine 
(San Diego, California). Paired end sequencing of $2 \times 300$ base pairs was performed using the MiSeq Reagent Kit v3 (Illumina, San Diego, California) according the manufacturers protocol.

Reads were trimmed using BBDuk (BBMap), assembled by MEGAHIT v1.0.3 (Li et al. 2015) and binned using an in-house pipeline, using different binning algorithms, including BinSanity (Graham et al. 2017), COCACOLA (Lu et al. 2017), CONCOCT (Alneberg et al. 2014), MaxBin 2.0 (Wu et al. 2016), and MetaBAT 2 (Kang et al. 2019). DAS Tool 1.0 was used for consensus binning (Sieber et al. 2018) and CheckM was used to assess the MAG quality (Parks et al. 2015). The average nucleotide identity using BLAST (ANIb) is calculated using JSpeciesWS software with standard settings (Richter et al. 2016). An up-to-date Bacterial Core Gene (UBCG) phylogenetic tree was constructed using RAxML (Stamatakis 2014) on CIPRES Science Gateway V. 3.3 platform (Miller et al. 2012). PROKKA and the MicroScope platform were used to automatically annotate the draft genome (Seemann 2014; Vallenet et al. 2013) and genomic features were manually checked.

\section{Results and discussion}

The Favara Grande is the main geothermal gasemitting area on Pantelleria Island, Italy. The soil in this region is acidic, of high temperature and exposed to geothermal gas emission (D'Alessandro et al. 2009). It is devoid of any plant growth. At the FAV2 site the following physicochemical parameters were observed: temperatures $60-67{ }^{\circ} \mathrm{C}, \mathrm{pH}$ 4-4.5, $\mathrm{CH}_{4}$ 1000-18,000 ppm and $\mathrm{H}_{2}$ 125-8400 ppm (see also Picone et al. 2020). $\mathrm{CH}_{4}$ and $\mathrm{H}_{2}$ concentrations were lowest close to soil surface, indicating active consumption of these gases. Metagenomic analysis of FAV2 soil samples revealed the presence of a diverse community of methanotrophs including those belonging to the phyla Verrucomicrobia and Gammaproteobacteria, at $6-11 \%$ and $2.5-3 \%$ relative abundance, respectively. No alphaproteobacterial methanotroph was detected (Picone et al. 2020) (Fig. 1). One of these FAV2 methanotrophs was classified as a Methylobacter species. The Methylobacter sp. B2 MAG was chosen for detailed analysis to achieve a better understanding of its metabolic potential and its relevance in the carbon cycle of geothermal soils.

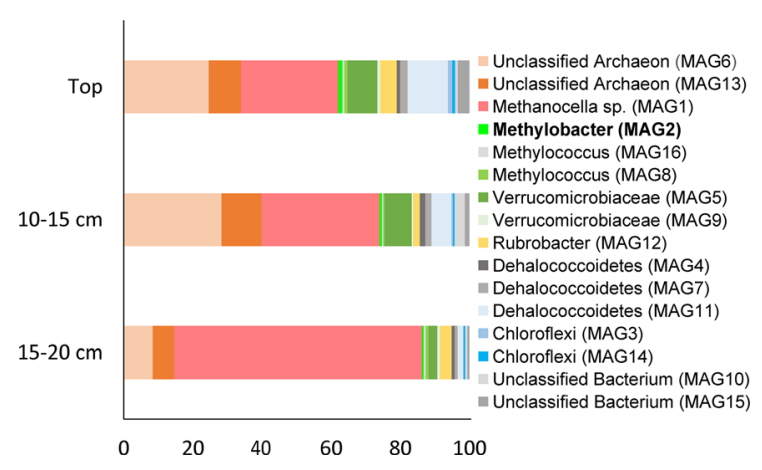

Fig. 1 The relative abundance of the different binned MAGs (completeness $>95 \%$ ) at the different depths of the geothermal soil of the Favara Grande, Pantelleria Island, Italy. The relative abundance of Methylobacter sp. B2 (MAG2) is $0.49 \%, 0.71 \%$ and $1.17 \%$ in the top layer, at $10-15 \mathrm{~cm}$ depth and at $15-20 \mathrm{~cm}$ depth, respectively

The MAG had a size of 4,086,539 bp, consisted of 134 contigs and had a GC content of $47.2 \%$. CheckM analysis revealed that the completeness of this MAG was $99.1 \%$ with only $0.4 \%$ contamination. A total of 3955 genes could be identified, of which 3902 were protein coding genes and 53 were RNA genes. Functions could be assigned to 2164 protein coding genes (Table 1). Moreover, $88.4 \%$ of the predicted genes were assigned into Clusters of Orthologous Groups and these COG functional categories are compiled in Table 2.

Table 1 Genome statistics

\begin{tabular}{ll}
\hline Attribute & Value \\
\hline Genome size (bp) & $4,086,539$ \\
DNA coding (bp) & $3,391,419$ \\
DNA G + C (\%) & 47.2 \\
DNA scaffolds & 134 \\
Total genes & 3955 \\
Protein coding genes & 3902 \\
RNA genes & 53 \\
rRNA genes & $3^{\mathrm{a}}$ \\
tRNA genes & 36 \\
Pseudo genes & 11 \\
Genes in internal clusters & - \\
Genes with function prediction & 2164 \\
Genes assigned to COGs & 3338 \\
\hline
\end{tabular}

${ }^{\mathrm{a}}$ See supplementary material 
Table 2 Number of genes associated with general COG functional category prediction
${ }^{\mathrm{a}}$ The total number is based on the number of protein coding genes (3902) in the genome

\begin{tabular}{|c|c|c|c|}
\hline Code & Value & $\%$ of total ${ }^{\mathrm{a}}$ & Description \\
\hline $\mathrm{J}$ & 168 & 4.25 & Translation, ribosomal structure and biogenesis \\
\hline A & 1 & 0.03 & RNA processing and modification \\
\hline K & 149 & 3.77 & Transcription \\
\hline $\mathrm{L}$ & 286 & 7.23 & Replication, recombination and repair \\
\hline B & 2 & 0.05 & Chromatin structure and dynamics \\
\hline $\mathrm{D}$ & 56 & 1.42 & Cell cycle control, cell division, chromosome partitioning \\
\hline V & 67 & 1.69 & Defense mechanisms \\
\hline $\mathrm{T}$ & 184 & 4.65 & Signal transduction mechanisms \\
\hline M & 245 & 6.19 & Cell wall/membrane/envelope biogenesis \\
\hline $\mathrm{N}$ & 98 & 2.48 & Cell motility \\
\hline $\mathrm{U}$ & 114 & 2.88 & Intracellular trafficking, secretion, and vesicular transport \\
\hline $\mathrm{O}$ & 158 & 3.99 & Posttranslational modification, protein turnover, chaperones \\
\hline $\mathrm{C}$ & 210 & 5.31 & Energy production and conversion \\
\hline G & 140 & 3.54 & Carbohydrate transport and metabolism \\
\hline E & 209 & 5.28 & Amino acid transport and metabolism \\
\hline $\mathrm{F}$ & 60 & 1.52 & Nucleotide transport and metabolism \\
\hline $\mathrm{H}$ & 130 & 3.29 & Coenzyme transport and metabolism \\
\hline I & 87 & 2.20 & Lipid transport and metabolism \\
\hline $\mathrm{P}$ & 187 & 4.73 & Inorganic ion transport and metabolism \\
\hline Q & 92 & 2.33 & Secondary metabolites biosynthesis, transport and catabolism \\
\hline $\mathrm{R}$ & 416 & 10.52 & General function prediction only \\
\hline S & 279 & 7.05 & Function unknown \\
\hline - & 615 & 15.60 & Not in COGs \\
\hline
\end{tabular}

\section{Phylogeny}

The draft genome of Methylobacter sp. B2 contained one 16S rRNA gene. This gene is located at the end of a contig and the rest of the ribosomal RNA operon could not be detected. This often happens during binning due to high conservation of the rRNA gene sequences. We were able to assemble a contig with the full rRNA operon using all reads from the metagenome dataset and the contig with the 16S rRNA gene in MAG as a seed (Supplementary Material). Phylogenetic analysis of the 16S rRNA gene revealed that this gene clusters together with Methylobacter species (Supplementary Fig. S1, Kumar et al. 2016; Tamura 1992). The closest cultivated relative is Methylobacter psychrophilus Z-0021, showing a 16S rRNA gene identity of only $96.5 \%$. Using a species boundary of $98.2 \%$, this $16 \mathrm{~S}$ rRNA identity indicated that the B2 MAG represented a novel species within the genus Methylobacter. Besides the 16S rRNA gene, pmoA is considered as molecular marker gene for defining methanotrophic taxa (Knief 2015). Phylogenetic analysis revealed of the $p m o A$ gene in this MAG did not cluster with other Methylobacter species (Supplementary Fig. S2, Saitou and Nei 1987; Zuckerkandl and Pauling 1965). This is not uncommon as for Methylobacter species, single-gene phylogenies resulted in inconsistencies, since this genus is assumed to be polyphyletic (i.e. having more than one common ancestor) (Orata et al. 2018). To circumvent this onegene-polyphyletic classification problem, an UBCG (Up-to-date bacterial core gene set) phylogenetic tree was constructed. Rather than a single gene, this tree is based on 92 bacterial core genes ( $\mathrm{Na}$ et al. 2018). The UBCG phylogenetic analysis showed that Methylobacter sp. B2 clusters within the Methylobacter genus (Fig. 2). Furthermore, average nucleotide identity (ANI) calculations gave values well below the threshold for species delimitation (95-96\%), demonstrating that this MAG indeed represents a novel species within the genus Methylobacter (Table 3) (Chun et al. 2018), for which we propose the name "Candidatus Methylobacter favarea” B2. 


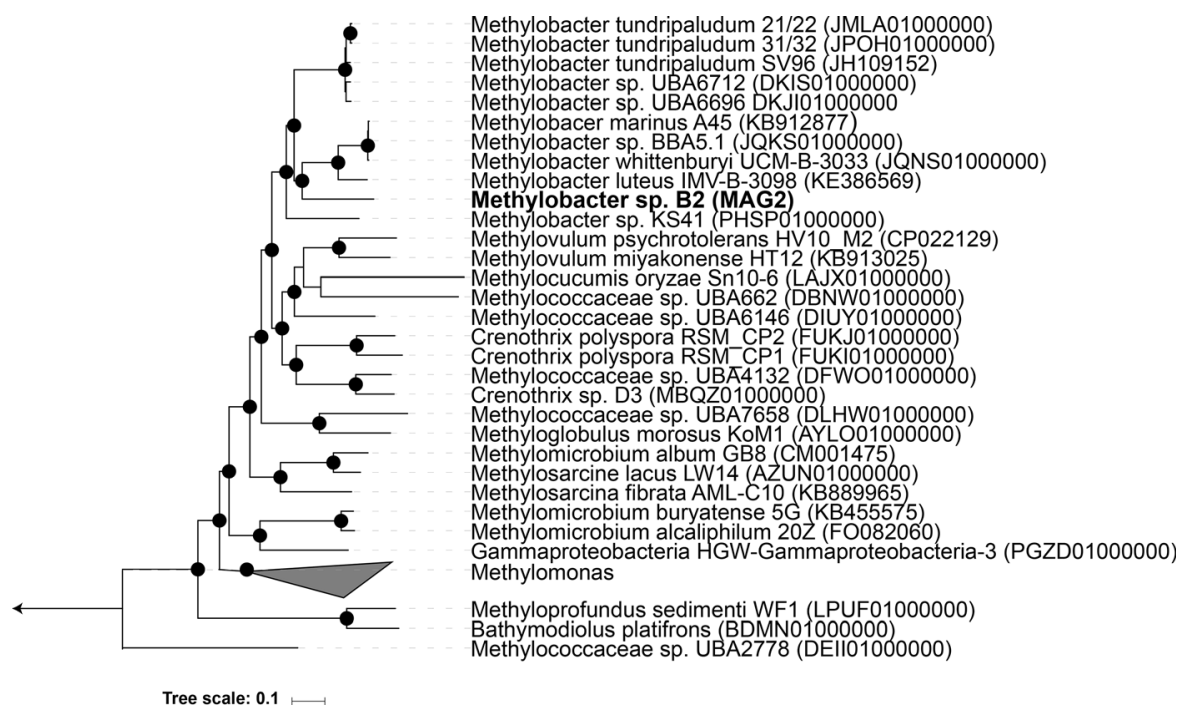

Fig. 2 Up-to-date Bacterial Core Gene (UBCG) phylogenetic tree of MAG2 and members of the family Methylomonaceae, all with a genome completeness of $>90 \%$. Hyphomicrobium denitrificans was used to root the tree, but removed from the tree for clarity. The tree was constructed using RAxmL. Bootstrap analysis was carried using 100 replications and percentage bootstrap values $>95 \%$ are indicated by black circles

Table 3 Average nucleotide identity (ANI) analysis of Methylobacter sp. B2 other representatives of this genus using JSpeciesWS software

\begin{tabular}{|c|c|c|c|c|c|c|c|c|c|c|}
\hline Strain & Strain name & 1 & 2 & 3 & 4 & 5 & 6 & 7 & 8 & 9 \\
\hline 1 & Methylobacter sp. B2 (MAG2) & & 73.7 & 75.9 & 75.9 & 72.8 & 74.6 & 74.1 & 75.9 & 73.3 \\
\hline 2 & Methylobacter marinus A45 & 73.4 & & 74.7 & 74.6 & 94.6 & 72.6 & 84.3 & 74.7 & 96.1 \\
\hline 3 & Methylobacter tundripaludum SV96 & 75.5 & 74.4 & & 95.4 & 70.6 & 75.4 & 74.7 & 95.6 & 74.2 \\
\hline 4 & Methylobacter tundripaludum $31 / 32$ & 75.5 & 74.3 & 95.3 & & 71.3 & 75.6 & 75.0 & 97.9 & 74.0 \\
\hline 5 & Methylobacter sp. BBA51 & 73.0 & 98.4 & 72.2 & 73.3 & & 71.9 & 82.7 & 73.5 & 74.8 \\
\hline 6 & Methylobacter sp. KS41 & 74.8 & 73.0 & 76.1 & 76.1 & 72.6 & & 73.4 & 76.2 & 72.4 \\
\hline 7 & Methylobacter luteus & 73.9 & 84.5 & 75.0 & 75.1 & 79.7 & 73.1 & & 75.2 & 83.6 \\
\hline 8 & Methylobacter tundripaludum 21/22 & 75.5 & 74.5 & 95.6 & 98.1 & 71.9 & 75.6 & 76.1 & & 74.3 \\
\hline 9 & Methylobacter whittenburyi & 73.3 & 98.2 & 74.6 & 74.6 & 80.3 & 72.2 & 84.8 & 74.6 & \\
\hline
\end{tabular}

All reference genomes show a completeness of at least $90 \%$ and a contamination of maximum $5 \%$

Analysis of the encoded metabolic potential

\section{Methanotrophy}

The first step in the methane oxidation pathway is the conversion of methane into methanol catalyzed by a membrane-bound or soluble methane monooxygenase. Analysis of the draft genome (see Fig. 3 for a schematic representation) revelaed one $p m o C A B$ gene cluster, encoding for the particulate membrane-bound, methane monooxygenase (pMMO). Typically, but not in all methanotrophs, the $p m o C A B$ gene cluster is complemented with a $p m o D$ gene. Recent studies show that $p m o D$ is essential for pMMO activity, and probably involved in copper incorporation (Fisher et al. 2018). In draft genome of " $\mathrm{Ca}$. Methylobacter favarea" B2, a homolog of the pmoD gene (METHB2_v1_630010) was present, but the gene is not located near the pmoCAB gene cluster. Genes encoding for the soluble methane monooxygenase (sMMO) were not detected. 


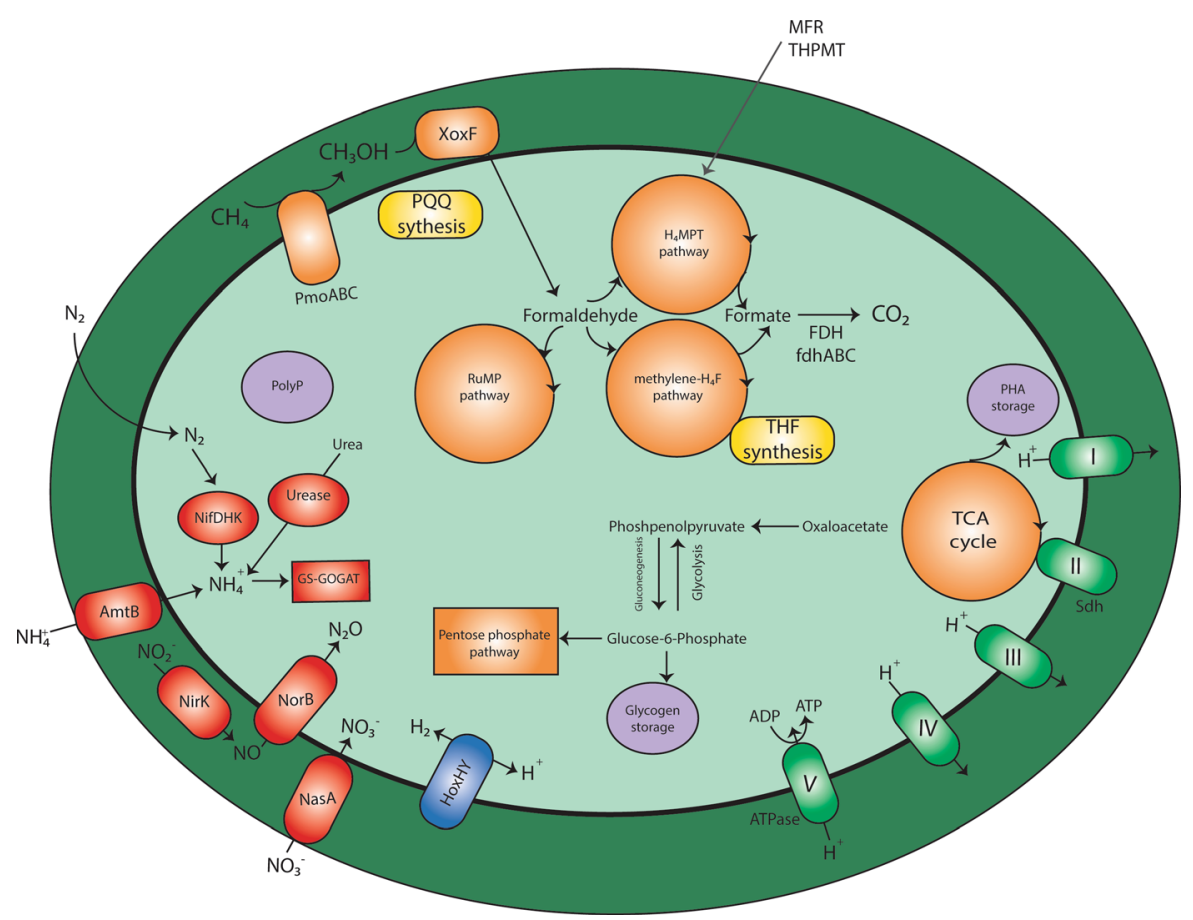

Fig. 3 Cell metabolism of "Ca. Methylobacter favarea" B2. Pmo particulate methane monoxygenase, XoxF XoxF-type methanol dehydrogenase, $F D H$ formate dehydrogenase,

"Ca. Methylobacter favarea" B2 catalyses the second step of the methane oxidation pathway, the conversion of methanol into formaldehyde, using a rare earth element (REE) and pyrroloquinoline quinone (PQQ) dependent XoxF-type methanol dehydrogenase (MDH) (Keltjens et al. 2014; Pol et al. 2014). In the genome, XoxF (METHB2_v1_30111), the catalytic MDH protein and XoxJ (METHB2_v1_30112), involved in protein binding for stability or electron transfer (Versantvoort et al. 2019), were encoded. The $x o x G$ gene, which encodes for the cytochrome $c_{L}$, that accepts electrons from MDH (Keltjens et al. 2014), could not be detected within the $x o x F / x o x J$ gene cluster. However, XoxFMDH systems do not follow a general organizational pattern at genomic level (Keltjens et al. 2014) and this MAG contains several mono-heme cytochromes with the heme-binding motif $\mathrm{CxxCH}$ and the conserved methionine typical for XoxG proteins (METHB2_v1_70040, METHB2_v1_200048, METHB2_v1_230021, METHB2_v1_350009, METHB2_v1_350010 and METHB2_v1_510007). These cytochromes could serve as electron acceptor
NifDHK nitrogenase, Nirk dissimilatory nitrite reductase, NorB nitric oxide reductase, $H o x H Y$ hydrogenase. Enzyme complexes of the electron transport chain are labeled by Roman numerals

for XoxF (Versantvoort et al. 2019). During methanol oxidation, electrons are transferred to the cytochrome via the cofactor PQQ and all genes for the synthesis of PQQ were present in this MAG. No genes encoding for the calcium-dependent MxaF-MDH could be identified.

XoxF-MDH requires lanthanides as metal cofactor (Pol et al. 2014) but the mechanism of their uptake in bacterial cells in not completely clarified. Recently, the lanthanide binding protein Lanmodulin was identified and postulated to function as cargo protein for lanthanides from a lanthanide transporter to $\mathrm{MDH}$ (Cotruvo et al. 2018). Lanmodulin seems not to be encoded in the MAG. Other studies indicated that TonB-dependent transporters might be involved in REE transport over the outer membrane, which are encoded by tonB or cirA genes (Ochsner et al. 2019; Roszczenko-Jasińska et al. 2020). The draft genome of "Ca. Methylobacter favarea" B2 contains several tonB and cirA genes (METHB2_v1_20123, METHB2_v1_30066, METHB2_v1_130008, METHB2_v1_200030 and METHB2_v1_300037) whereby METHB2_v1_20123 shows the highest 
similarity (33\% based on amino acid composition) with the putative REE transporter of Methylorubrum extorquens PA1. None of these transporters are located near the methanol dehydrogenase genes as in Methylorubrum extorquens PA1 (Ochsner et al. 2019).

In the next step of the $\mathrm{CH}_{4}$ oxidation pathway, formaldehyde is oxidized to formate. Formaldehyde is a key metabolite, since it is used for carbon assimilation by proteobacterial methanotrophs. Furthermore, formaldehyde oxidation is considered to be essential, since intracellular concentrations of toxic formaldehyde should remain low (Chistoserdova 2011). However, this MAG does not seem to contain a gene encoding for formaldehyde dehydrogenase, which prevents direct formaldehyde to formate conversion. In vitro studies showed that XoxF-MDH from $M$. extorquens AM1 and M. fumariolicum SolV can use formaldehyde as substrate leading to the hypothesis that XoxF-type MDHs oxidize methanol into formate (Pol et al. 2014; Good et al. 2018). In contrast, in vivo, the XoxF-type MDH of $M$. extorquens AM1 was shown to produce formaldehyde, which can be used for carbon assimilation (Good et al. 2018).

In $M$. extorquens AM1 the lanthanide-dependent ethanol dehydrogenase ExaF was involved in formaldehyde oxidation (Good et al. 2018). As there was no ethanol dehydrogenase nor a MxaF-MDH found in the draft genome of " $\mathrm{Ca}$. Methylobacter favarea" B2 to oxidize formaldehyde, indicating that this strain possibly uses a different pathway for formaldehyde oxidation. The most widespread formaldehyde conversion pathway is the glutathionelinked formaldehyde oxidation pathway. The first step in this pathway is the reaction of formaldehyde with glutathione. The glutathione-dependent formaldehyde dehydrogenase enzyme accelerates this spontaneous reaction (Goenrich et al. 2002). This enzyme could be detected in the " $\mathrm{Ca}$. Methylobacter favarea" B2 MAG (METHB2_v1_3500004). In the following two steps, formate is formed by glutathione-dependent formaldehyde dehydrogenase and S-formylglutathione hydrolase, however none of these enzymes could be detected within " $\mathrm{Ca}$. Methylobacter favarea” B2.

Alternatively, formaldehyde can be converted to formate by the tetrahydromethanopterin $\left(\mathrm{H}_{4} \mathrm{MPT}\right)$ pathway or the methylene-tetrahydrofolate (methylene- $\mathrm{H}_{4} \mathrm{~F}$ ) pathway. The genes for both pathways were detected in draft genome of " $\mathrm{Ca}$. Methylobacter favarea" B2, suggesting that this strain can use both pathways, as described for Methylococcus capsulatus Bath (Chistoserdova et al. 2005). Proteomics studies revealed that the $\mathrm{H}_{4}$ MPT-pathway is used for formaldehyde to formate conversion in $M$. capsulatus Bath (Kao et al. 2004). Whether " $C a$. Methylobacter favarea" B2 uses the $\mathrm{H}_{4}$ MPT-pathway or the methylene- $\mathrm{H}_{4} \mathrm{~F}$-pathway remains uncertain. However, the genes for the synthesis of the cofactors methanofuran (MFR) and tetrahydromethanopterin (THPMT) were lacking, whereas the genes needed for the synthesis of tetrahydrofolate (THF) were present. This suggests that the $\mathrm{H}_{4}$ MPT-pathway can only be used whenever the cofactors are supplied by other members of the microbial community.

Formate dehydrogenase catalyses the final step in the methane oxidation pathway, namely the conversion of formate into $\mathrm{CO}_{2}$. Typically, methanotrophs encode for multiple formate dehydrogenases (Chistoserdova 2011; Flynn et al., 2016). "Ca. Methylobacter favarea" B2 encodes for two different formate dehydrogenases, a NAD-dependent FDH encoded by a single gene (METHB2_v1_310032) and a molybdopterin containing formate dehydrogenase encoded by the three genes fdhABC (METHB2_v1_500021, METHB2_v1_500022 and METHB2_v1_500023).

\section{Energy conservation and respiration}

“Ca. Methylobacter favarea” $\mathrm{B} 2$ uses $\mathrm{O}_{2}$ as terminal electron acceptor. The NADH:ubiquinone reductase genes (complex I, пиоABCDEFGHIJKLMN) were found in the MAG, together with genes encoding the succinate dehydrogenase (complex II), cytochrome $\mathrm{bc}_{1}$ (complex III) and cytochrome-c-oxidase (complex IV) complexes. The proton motive force generated by the respiratory chain can be used by the ATPgenerating ATPase (complex V).

\section{Carbon fixation}

"Ca. Methylobacter favarea" B2 uses the ribulosemono-phosphate (RuMP) pathway for carbon fixation, as do other Methylobacter species (Flynn et al. 2016). Interestingly, a nearly complete serine pathway could also be detected in the genome of " $\mathrm{Ca}$. Methylobacter favarea" B2. Usually, the serine pathway is used by alphaproteobacterial methanotrophs as carbon fixation pathway and gammaproteobacterial methanotrophs 
only contain parts of the serine pathway. Typically, gammaproteobacterial methanotrophs lack the enzyme phosphoenolpyruvate carboxylase (Chistoserdova 2011), however, the " $\mathrm{Ca}$. Methylobacter favarea" B2 MAG encodes for every enzyme in the serine pathway except the serine-glyoxylate aminotransferase. In contrast to Verrucomicrobial methanotrophs (Khadem et al. 2011), the Calvin-BensonBassham cycle cannot be used for carbon fixation in "Ca. Methylobacter favarea" B2, since RuBisCO genes are lacking.

\section{Alternative substrates}

All genes for the glycolysis and gluconeogenesis were found and the TCA cycle genes were present. Genes of the glyoxylate shunt were partially detected, the gene encoding for isocitrate lyase is found in the draft genome, but a gene encoding for malate synthase could not be detected. The pentose phosphate pathway was present. Furthermore, transporters for a variety of organic molecules could be predicted. This indicates that " $\mathrm{Ca}$. Methylobacter favarea" B2 could benefit from a mixotrophic lifestyle or survival modus. Furthermore, "Ca. Methylobacter favarea" B2 seemed to be able to store a variety of carbon compounds, including glycogen, polyhydroxybutyrate and polyphosphates.

The " $C a$. Methylobacter favarea" B2 MAG contained an oxygen tolerant NAD-coupled hydrogenase, belonging to group $3 \mathrm{~d}$ bidirectional hydrogenases (Greening et al. 2016). $\mathrm{H}_{2}$ is an abundant electron donor in the FAV2 soils (D'Alessandro et al. 2009; Gagliano et al. 2016; Picone et al. 2020) and simultaneous $\mathrm{CH}_{4}$ and $\mathrm{H}_{2}$ oxidation is reported for different methanotrophs (Chen and Yoch 1987; Hanczar et al. 2002; Mohammadi et al. 2017; Carere et al. 2017). However, it is unlikely that " $\mathrm{Ca}$. Methylobacter favarea" B2 can grow as 'Knallgas' bacterium, since it requires formaldehyde for carbon fixation. A mechanism for $\mathrm{CO}_{2}$ fixation is not detected in this MAG.

\section{Nitrogen}

Ammonia can be used as nitrogen source and is assimilated using either the glutamate dehydrogenase (METHB2_v1_670013) or the glutamine synthetase (METHB2_v1_100031) and glutamate synthase
(METHB2_v1_410017). Nitrate and nitrite could also serve as nitrogen source. The activity of the assimilatory nitrate reductase NasA (METHB2_v1_40058) and nitrite reductase NirBD (METHB2_v1_40055, METHB2_v1_40054) would results in the production of ammonium. Genes encoding urease (METHB2_v1_20024, METHB2_v1_20025 and METHB2_v1_20026) and nitrogenase (nifHDK, METHB2_v1_180032, METHB2_v1_180033 and METHB2_v1_180034) were present, indicating that urea and $\mathrm{N}_{2}$ could also be used as nitrogen source in this severely $\mathrm{N}$-limited ecosystem. The genes encoding the nitrite reductases NirK (METHB2_v1_00392), NirS (METHB2_v1_02231) and nitric oxide reductase NorBC (METHB2_v1_01347, METHB2_v1_01348) were found, suggesting that " $C a$. Methylobacter favarea" B2 may be capable of partial denitrification.

\section{pH homeostasis}

In order for " $\mathrm{Ca}$. Methylobacter favarea" B2 to thrive in an acid environment, it is important to control the intracellular $\mathrm{pH}$. The maintenance of $\mathrm{pH}$ homeostasis is a result of restriction of proton permeation, internal consumption of protons and enhancement of proton pumps (Guan and Liu 2020). ATPases can pump out electrons and release acid stress, but this requires ATP (Liu et al. 2015a). "Ca. Methylobacter favarea" B2 encodes for different $\mathrm{Na}^{+} / \mathrm{H}^{+}$antiporters (METHB2_v1_30076, METHB2_v1_70105, METHB2_v1_150016 and METHB2_v1_840011), which might be important for proton exchange as well (Slonczewski et al. 2009).

There are different mechanisms on intracellular proton consumption, which generates alkaline products. Several microorganisms use an amino-acid tolerance system to decrease the intracellular $\mathrm{pH}$. However, both the arginine deaminase (ADI) system and the glutamate-dependent acid tolerance system (Liu et al. 2015b; Reeve and Reid 2016; Shabayek and Spellerberg 2017) could not be detected in the draft genome of " $\mathrm{Ca}$. Methylobacter favarea” B2 Instead, "Ca. Methylobacter favarea" B2 could use the urease system for proton consumption. Since the genome encodes a urease, this enzyme can transform urea into ammonia and $\mathrm{CO}_{2}$ at the expense of a proton, whereby it regulates the internal $\mathrm{pH}$ (Miller and Maier 2014). Interestingly, the urease genes are widespread amongst the geothermal microorganisms of the Favara 
Grande (Picone et al. 2020), indicating that this urease system might be an important mechanisms in $\mathrm{pH}$ homeostasis within geothermal microorganisms.

\section{Ecological role}

Typically, Methylobacter species are found in freshwater oxic sediments, terrestrial habitats and marine ecosystems, where they account for a large fraction of aerobic methanotrophy (Hao et al., 2020; Khatri et al. 2019; Smith et al. 2018). Thermoacidophilic Methylobacter species have, so far, not been isolated. Thermophilic Gammaproteobacteria are found within the family Methylothermaceae and the genus Methylocaldum (Houghton et al. 2019) and not within the family Methylomonaceae. Previously, 16S rRNA gene amplicon sequencing and metagenomic sequencing revealed that Methylobacter sp. are abundant methanotrophs in the geothermal soils of the Favara Grande (Gagliano et al. 2016). Other geothermal soil microbial communities, such as the one in the Solfatara Crater near Naples, Italy, did not show the presence of Methylobacter species (Crognale et al., 2018), indicating that we still have to learn more about the metabolic diversity of this important group of methanotrophs.

Acknowledgements $\mathrm{CH}$, NP and HOdC were supported by the European Research Council (ERC Advanced Grant Project VOLCANO 669371), LP was supported by the Netherlands Earth System Science Centre (NESSC 024002001) and MSMJ was supported by the European Research Council (ERC Advanced Grant Project Eco_MoM 339880) and The Soehngen Institute of Anaerobic Microbiology (SIAM 024002002).

Author contributions $\mathrm{CH}$, NP, AP, MJ, and HOdC designed the projects and experiments. $\mathrm{CH}, \mathrm{NP}, \mathrm{AP}, \mathrm{AG}, \mathrm{WD}$ ' A, PQ, and HOdC sampled the geothermal soils. $\mathrm{CH}$ and NP performed DNA extraction. TA sequenced the genome. JF and TA reconstructed the genome and $\mathrm{FH}, \mathrm{SV}, \mathrm{LP}, \mathrm{CH}, \mathrm{NP}$ and HOdC annotated the genome. $\mathrm{CH}, \mathrm{FH}, \mathrm{SV}$ and HOdC wrote the manuscript. All authors contributed to revision of the manuscript, and read and approved the submitted version.

Funding The research was supported by the European Research Council (ERC Advanced Grant Project VOLCANO 669371 and ERC Advanced Grant project Eco_MoM 339880), by the Netherlands Earth System Science Centre (NESSC 024002001) and by The Soehngen Institute of Anaerobic Microbiology (SIAM 024002002).
Availability of data and materials DNA sequences (raw sequence reads and MAGs) have been deposited in NCBI BioProject database with accession number PRJEB36447. The draft genome is available at NCBI under Accession No. GCA_902806695.

\section{Compliance with ethical standards}

Conflict of interest The authors declare that the research was conducted in the absence of any commercial or financial relationships that could be construed as a potential conflict of interest.

Ethical standards This article does not contain any studies with human participants or animals performed by any of the authors.

Open Access This article is licensed under a Creative Commons Attribution 4.0 International License, which permits use, sharing, adaptation, distribution and reproduction in any medium or format, as long as you give appropriate credit to the original author(s) and the source, provide a link to the Creative Commons licence, and indicate if changes were made. The images or other third party material in this article are included in the article's Creative Commons licence, unless indicated otherwise in a credit line to the material. If material is not included in the article's Creative Commons licence and your intended use is not permitted by statutory regulation or exceeds the permitted use, you will need to obtain permission directly from the copyright holder. To view a copy of this licence, visit http://creativecommons.org/licenses/by/4.0/.

\section{References}

Allen GC, Flores-Vergara MA, Krasynanski S, Kumar S, Thompson WF (2006) A modified protocol for rapid DNA isolation from plant tissues using cetyltrimethylammonium bromide. Nat Protoc 1:2320-2325. https://doi.org/10.1038/ nprot.2006.384

Alneberg J, Bjarnason BS, De Bruijn I, Schirmer M, Quick J, Ijaz UZ, Lahti L, Loman NJ, Andersson AF, Quince C (2014) Binning metagenomic contigs by coverage and composition. Nat Methods 11:1144-1146. https://doi.org/ 10.1038/nmeth.3103

Carere CR, Hards K, Houghton KM, Power JF, Mcdonald B, Collet C, Gapes DJ, Sparling R, Boyd ES, Cook GM, Greening C, Stott MB (2017) Mixotrophy drives niche expansion of verrucomicrobial methanotrophs. ISME J 11:2599-2610. https://doi.org/10.1038/ismej.2017.112

Chen YP, Yoch DC (1987) Regulation of two nickel-requiring (inducible and constitutive) hydrogenases and their coupling to nitrogenase in Methylosinus trichosporium OB3b. J Bacteriol 169:4778-4783. https://doi.org/10.1128/jb.169. $10.4778-4783.1987$

Chistoserdova L (2011) Modularity of methylotrophy, revisited. Environ Microbiol 13:2603-2622. https://doi.org/10.1111/ j.1462-2920.2011.02464.x 
Chistoserdova L, Vorholt JA, Lidstrom ME (2005) A genomic view of methane oxidation by aerobic bacteria and anaerobic archaea. Genome Biol 6:208. https://doi.org/10.1186/ gb-2005-6-2-208

Chun J, Oren A, Ventosa A, Christensen H, Arahal DR, Da Costa MS, Rooney AP, Yi H, Xu XW, De Meyer S, Trujillo ME (2018) Proposed minimal standards for the use of genome data for the taxonomy of prokaryotes. Int J Syst Evol Microbiol 68:461-466. https://doi.org/10.1099/ijsem. 0.002516

Cotruvo JA Jr, Featherston ER, Mattocks JA, Ho JV, Laremore TN (2018) Lanmodulin: a highly selective lanthanidebinding protein from a lanthanide-utilizing bacterium. J Am Chem Soc 140:15056-15061. https://doi.org/10. 1021/jacs.8b09842

Crognale S, Venturi S, Tassi F, Rossetti S, Rashed H, Cabassi J, Capecchiacci F, Nisi B, Vaselli O, Morrison HG, Sogin ML, Fazi S (2018) Microbiome profiling in extremely acidic soils affected by hydrothermal fluids: the case of the Solfatara Crater (Campi Flegrei, southern Italy). FEMS Microbiol Ecol 94:fiy190. https://doi.org/10.1093/femsec/ fiy 190

D’Alessandro W, Bellomo S, Brusca L, Fiebig J, Longo M, Martelli M, Pecoraino G, Salerno F (2009) Hydrothermal methane fluxes from the soil at Pantelleria island (Italy). J Volcanol Geotherm Res 187:147-157. https://doi.org/10. 1016/j.jvolgeores.2009.08.018

Dunfield PF, Yuryev A, Senin P, Smirnova AV, Stott MB, Hou S, Ly B, Saw JH, Zhou Z, Ren Y, Wang J, Mountain BW, Crowe MA, Weatherby TM, Bodelier PLE, Liesack W, Feng L, Wang L, Alam M (2007) Methane oxidation by an extremely acidophilic bacterium of the phylum Verrucomicrobia. Nature 450:879-882. https://doi.org/10.1038/ nature 06411

Erikstad H-A, Ceballos RM, Smestad NB, Birkeland N-K (2019) Global biogeographic distribution patterns of thermoacidophilic Verrucomicrobia methanotrophs suggest allopatric evolution. Front Microbiol 10:1129. https://doi. org/10.3389/fmicb.2019.01129

Etiope G, Klusman RW (2002) Geologic emissions of methane to the atmosphere. Chemosphere 49:777-789. https://doi. org/10.1016/S0045-6535(02)00380-6

Fisher OS, Kenney GE, Ross MO, Ro SY, Lemma BE, Batelu S, Thomas PM, Sosnowski VC, Dehart CJ, Kelleher NL, Stemmler TL, Hoffman BM, Rosenzweig AC (2018) Characterization of a long overlooked copper protein from methane- and ammonia-oxidizing bacteria. Nat Commun 9:4276. https://doi.org/10.1038/s41467-018-06681-5

Flynn JD, Hirayama H, Sakai Y, Dunfield PF, Klotz MG, Knief C, Op den Camp HJM, Jetten MSM, Khmelenina VN, Trotsenko YA, Murrell JC, Semrau JD, Svenning MM, Stein LY, Kyrpides N, Shapiro N, Woyke T, Bringel F, Vuilleumier S, Dispirito AA, Kalyuzhnaya MG (2016) Draft genome sequences of gammaproteobacterial methanotrophs isolated from marine ecosystems. Genome Announc 4:e01629. https://doi.org/10.1128/genomeA. 01629-15

Gagliano AL, D'Alessandro W, Tagliavia M, Parello F, Quatrini $P$ (2014) Methanotrophic activity and diversity of methanotrophs in volcanic geothermal soils at Pantelleria
(Italy). Biogeosciences 11:5865-5875. https://doi.org/10. 5194/bg-11-5865-2014

Gagliano AL, Tagliavia M, D'Alessandro W, Franzetti A, Parello F, Quatrini P (2016) So close, so different: geothermal flux shapes divergent soil microbial communities at neighbouring sites. Geobiology 14:150-162. https://doi. org/10.1111/gbi.12167

Goenrich M, Bartoschek S, Hagemeier $\mathrm{CH}$, Griesinger C, Vorholt JA (2002) A Glutathione-dependent Formaldehyde-activating Enzyme (Gfa) from Paracoccus denitrificans Detected and Purified via Two-dimensional Proton Exchange NMR Spectroscopy. J Biol Chem 277(5):30693072. https://doi.org/10.1074/jbc.C100579200

Good NM, Walser ON, Moore RS, Suriano CJ, Huff AF, Martínez-Gómez NC (2018) Investigation of lanthanide-dependent methylotrophy uncovers complementary roles for alcohol dehydrogenase enzymes. bioRxiv 329011. https:// doi.org/10.1101/329011

Graham ED, Heidelberg JF, Tully BJ (2017) BinSanity: unsupervised clustering of environmental microbial assemblies using coverage and affinity propagation. PeerJ 5:e3035. https://doi.org/10.7717/peerj.3035

Greening C, Biswas A, Carere CR, Jackson CJ, Taylor MC, Stott MB, Cook GM, Morales SE (2016) Genomic and metagenomic surveys of hydrogenase distribution indicate $\mathrm{H}_{2}$ is a widely utilised energy source for microbial growth and survival. ISME J 10:761-777. https://doi.org/10.1038/ ismej.2015.153

Guan N, Liu L (2020) Microbial response to acid stress: mechanisms and applications. Appl Microbiol Biotechnol 104:51-65. https://doi.org/10.1007/s00253-019-10226-1

Hanczar T, Csaki R, Bodrossy L, Murrell JC, Kovacs KL (2002) Detection and localization of two hydrogenases in Methylococcus capsulatus (Bath) and their potential role in methane metabolism. Arch Microbiol 177:167-172. https://doi.org/10.1007/s00203-001-0372-4

Hanson RS, Hanson TE (1996) Methanotrophic bacteria. Microbiol Rev 60:439-447

Hao Q, Liu F, Zhang Y, Wang O, Xiao L (2020) Methylobacter accounts for strong aerobic methane oxidation in the Yellow River Delta with characteristics of a methane sink during the dry season. Sci Total Environ 704:135383. https://doi.org/10.1016/j.scitotenv.2019.135383

Houghton KM, Carere CR, Stott MB, McDonald IR (2019) Thermophilic methanotrophs: in hot pursuit. FEMS Microbiol Ecol 95:fiz125. https://doi.org/10.1093/femsec/ fiz125

Islam T, Jensen S, Reigstad LJ, Larsen O, Birkeland N-K (2008) Methane oxidation at 55 degrees $\mathrm{C}$ and $\mathrm{pH} 2$ by a thermoacidophilic bacterium belonging to the Verrucomicrobia phylum. Proc Natl Acad Sci USA 105:300-304. https:// doi.org/10.1073/pnas.0704162105

Kang DD, Li F, Kirton E, Thomas A, Egan R, An H, Wang Z (2019) MetaBAT 2: an adaptive binning algorithm for robust and efficient genome reconstruction from metagenome assemblies. PeerJ 7:e7359. https://doi.org/10. 7717/peerj.7359

Kao WC, Chen YR, Yi EC, Lee H, Tian Q, Wu KM, Tsai SF, Yu SS, Chen YJ, Aebersold R, Chan SI (2004) Quantitative proteomic analysis of metabolic regulation by copper ions in Methylococcus capsulatus (Bath). J Biol Chem 
279:51554-51560.

M408013200

Keltjens JT, Pol A, Reimann J, Op den Camp HJM (2014) PQQdependent methanol dehydrogenases: rare-earth elements make a difference. Appl Microbiol Biotechnol 98:6163-6183. https://doi.org/10.1007/s00253-014-57668

Khadem AF, Pol A, Wieczorek A, Mohammadi SS, Francoijs K-J, Stunnenberg HG, Jetten MSM, Op den Camp HJM (2011) Autotrophic methanotrophy in Verrucomicrobia: Methylacidiphilum fumariolicum SolV uses the CalvinBenson-Bassham cycle for carbon dioxide fixation. J Bacteriol 193:4438-4446. https://doi.org/10.1128/jb.00407-11

Khatri K, Mohite JA, Pandit PS, Bahulikar R, Rahalkar MC (2019) Description of ' $C a$. Methylobacter oryzae' KRF1, a novel species from the environmentally important Methylobacter clade 2. Antonie Van Leeuwenhoek 113:729-735. https://doi.org/10.1007/s10482-019-01369-2

Knief C (2015) Diversity and habitat preferences of cultivated and uncultivated aerobic methanotrophic bacteria evaluated based on $p m o A$ as molecular marker. Front Microbiol 6:1346-1346. https://doi.org/10.3389/fmicb.2015.01346

Kumar S, Stecher G, Tamura K (2016) MEGA7: molecular evolutionary genetics analysis version 7.0 for bigger datasets. Mol Biol Evol 33:1870-1874. https://doi.org/10. 1093/molbev/msw054

Li D, Liu CM, Luo R, Sadakane K, Lam TW (2015) MEGAHIT: an ultra-fast single-node solution for large and complex metagenomics assembly via succinct de Bruijn graph. Bioinformatics 31:1674-1676. https://doi.org/10.1093/ bioinformatics/btv033

Liu Y, Lv C, Xu Q, Li S, Huang H, Ouyang P (2015a) Enhanced acid tolerance of Rhizopus oryzae during fumaric acid production. Bioprocess Biosystems Eng 38:323-328. https://doi.org/10.1007/s00449-014-1272-8

Liu Y, Tang H, Lin Z, Xu P (2015b) Mechanisms of acid tolerance in bacteria and prospects in biotechnology and bioremediation. Biotechnol Adv 33:1484-1492. https:// doi.org/10.1016/j.biotechadv.2015.06.001

Lu YY, Chen T, Fuhrman JA, Sun F (2017) COCACOLA: binning metagenomic contigs using sequence COmposition, read CoverAge, CO-alignment and paired-end read LinkAge. Bioinformatics 33:791-798. https://doi.org/10. 1093/bioinformatics/btw290

Miller EF, Maier RJ (2014) Ammonium metabolism enzymes aid Helicobacter pylori acid resistance. J Bacteriol 196:3074-3081. https://doi.org/10.1128/jb.01423-13

Miller MA, Pfeiffer W, Schwartz T (2012) The CIPRES science gateway: enabling high-impact science for phylogenetics researchers with limited resources. In: XSEDE '12: proceedings of the 1 st conference of the extreme science and engineering discovery environment: bridging from the extreme to the campus and beyond, vol 39, pp 1-8. https:// doi.org/10.1145/2335755.2335836

Mohammadi S, Pol A, van Alen TA, Jetten MSM, Op den Camp HJM (2017) Methylacidiphilum fumariolicum SolV, a thermoacidophilic 'Knallgas' methanotroph with both an oxygen-senstitive and-insensitive hydrogenase. ISME J 11:945-958. https://doi.org/10.1038/ismej.2016.171
Murrell JC (1992) Genetics and molecular biology of methanotrophs. FEMS Microbiol Rev 8:233-248. https://doi.org/ 10.1111/j.1574-6968.1992.tb04990.x

Na SI, Kim YO, Yoon SH, Ha SM, Baek I, Chun J (2018) UBCG: up-to-date bacterial core gene set and pipeline for phylogenomic tree reconstruction. J Microbiol 56:280-285. https://doi.org/10.1007/s12275-018-8014-6

Niemann H, Lösekann T, De Beer D, Elvert M, Nadalig T, Knittel K, Amann R, Sauter EJ, Schlüter M, Klages M, Foucher JP, Boetius A (2006) Novel microbial communities of the Haakon Mosby mud volcano and their role as a methane sink. Nature 443:854-858. https://doi.org/10. 1038/nature05227

Ochsner AM, Hemmerle L, Vonderach T, Nüssli R, BortfeldMiller M, Hattendorf B, Vorholt JA (2019) Use of rareearth elements in the phyllosphere colonizer Methylobacterium extorquens PA1. Mol Microbiol 111:1152-1166. https://doi.org/10.1111/mmi.14208

Op den Camp HJM, Islam T, Stott MB, Harhangi HR, Hynes A, Schouten S, Jetten MSM, Birkeland N-K, Pol A, Dunfield PF (2009) Environmental, genomic and taxonomic perspectives on methanotrophic Verrucomicrobia. Environ Microbiol Rep 1:293-306. https://doi.org/10.1111/j.17582229.2009.00022.x

Orata FD, Meier-Kolthoff JP, Sauvageau D, Stein LY (2018) Phylogenomic analysis of the gammaproteobacterial methanotrophs (order Methylococcales) calls for the reclassification of members at the genus and species levels. Front Microbiol 9:3162. https://doi.org/10.3389/fmicb. 2018.03162

Parks DH, Imelfort M, Skennerton CT, Hugenholtz P, Tyson GW (2015) CheckM: assessing the quality of microbial genomes recovered from isolates, single cells, and metagenomes. Genome Res 25:1043-1055. https://doi.org/10. 1101/gr.186072.114

Picone N, Hogendoorn C, Cremers G, Poghosyan L, Pol A, van Alen TA, Gagliano AL, D'Alessandro W, Quatrini P, Jetten MSM, Op den Camp HJM, Berben T (2020) Geothermal gases shape the microbial community of the volcanic soil of Pantelleria, Italy. mSystems 5:e00517-e520. https:// doi.org/10.1128/mSystems.00517-20

Pol A, Heijmans K, Harhangi HR, Tedesco D, Jetten MSM, Op den Camp HJM (2007) Methanotrophy below pH 1 by a new Verrucomicrobia species. Nature 450:874-878. https://doi.org/10.1038/nature06222

Pol A, Barends TRM, Dietl A, Khadem AF, Eygensteyn J, Jetten MSM, Op den Camp HJM (2014) Rare earth metals are essential for methanotrophic life in volcanic mudpots. Environ Microbiol 16:255-264. https://doi.org/10.1111/ 1462-2920.12249

Rasigraf O, Kool DM, Jetten MS, Sinninghe Damste JS, Ettwig KF (2014) Autotrophic carbon dioxide fixation via the Calvin-Benson-Bassham cycle by the denitrifying methanotroph "Candidatus Methylomirabilis oxyfera". Appl Environ Microbiol 80:2451-2460. https://doi.org/10. 1128/aem.04199-13

Reeve BWP, Reid SJ (2016) Glutamate and histidine improve both solvent yields and the acid tolerance response of Clostridium beijerinckii NCP 260. J Appl Microbiol 120:1271-1281. https://doi.org/10.1111/jam.13067 
Richter M, Rossello-Mora R, Oliver Glockner F, Peplies J (2016) JSpeciesWS: a web server for prokaryotic species circumscription based on pairwise genome comparison. Bioinformatics 32:929-931. https://doi.org/10.1093/ bioinformatics/btv681

Roszczenko-Jasińska P, Vu HN, Subuyuj GA, Crisostomo RV, Cai J, Lien NF, Clippard EJ, Ayala EM, Ngo RT, Yarza F, Wingett JP, Raghuraman C, Hoeber CA, Martinez-Gomez NC, Skovran E (2020) Gene products and processes contributing to lanthanide homeostasis and methanol metabolism in Methylorubrum extorquens AM1. Sci Rep 10:12663. https://doi.org/10.1038/s41598-020-69401-4

Saitou N, Nei M (1987) The neighbor-joining method: a new method for reconstructing phylogenetic trees. Mol Biol Evol 4:406-425. https://doi.org/10.1093/oxfordjournals. molbev.a040454

Seemann T (2014) Prokka: rapid prokaryotic genome annotation. Bioinformatics 30:2068-2069. https://doi.org/10. 1093/bioinformatics/btu153

Shabayek S, Spellerberg B (2017) Acid stress response mechanisms of group B Streptococci. Front Cell Infect Microbiol 7:395. https://doi.org/10.3389/fcimb.2017.00395

Sharp CE, Smirnova AV, Graham JM, Stott MB, Khadka R, Moore TR, Grasby SE, Strack M, Dunfield PF (2014) Distribution and diversity of Verrucomicrobia methanotrophs in geothermal and acidic environments. Environ Microbiol 16:1867-1878. https://doi.org/10.1111/14622920.12454

Sieber CMK, Probst AJ, Sharrar A, Thomas BC, Hess M, Tringe SG, Banfield JF (2018) Recovery of genomes from metagenomes via a dereplication, aggregation and scoring strategy. Nat Microbiol 3:836-843. https://doi.org/10. 1038/s41564-018-0171

Slonczewski JL, Fujisawa M, Dopson M, Krulwich TA (2009) Cytoplasmic $\mathrm{pH}$ measurement and homeostasis in Bacteria and Archaea. Adv Microb Physiol 55(1-79):317. https:// doi.org/10.1016/S0065-2911(09)05501-5

Smith GJ, Angle JC, Solden LM, Borton MA, Morin TH, Daly RA, Johnston MD, Stefanik KC, Wolfe R, Gil B, Wrighton KC (2018) Members of the genus Methylobacter are inferred to account for the majority of aerobic methane oxidation in oxic soils from a freshwater wetland. $\mathrm{mBio}$ 9:e00815-e00818. https://doi.org/10.1128/mBio.00815-18
Stamatakis A (2014) RAxML version 8: a tool for phylogenetic analysis and post-analysis of large phylogenies. Bioinformatics 30:1312-1313. https://doi.org/10.1093/ bioinformatics/btu033

Tamura K (1992) Estimation of the number of nucleotide substitutions when there are strong transition-transversion and G+C-content biases. Mol Biol Evol 9:678-687. https://doi. org/10.1093/oxfordjournals.molbev.a040752

Vallenet D, Belda E, Calteau A, Cruveiller S, Engelen S, Lajus A, Le Fevre F, Longin C, Mornico D, Roche D, Rouy Z, Salvignol G, Scarpelli C, Thil Smith AA, Weiman M, Medigue C (2013) MicroScope-an integrated microbial resource for the curation and comparative analysis of genomic and metabolic data. Nucl Acids Res 41:D636D647. https://doi.org/10.1093/nar/gks1194

van Teeseling MCF, Pol A, Harhangi HR, van der Zwart S, Jetten MSM, Op den Camp HJM, Van Niftrik L (2014) Expanding the verrucomicrobial methanotrophic world: description of three novel species of Methylacidimicrobium gen. nov. Appl Environ Microbiol 80:6782-6791. https://doi.org/10.1128/aem.01838-14

Versantvoort W, Pol A, Daumann LJ, Larrabee JA, Strayer AH, Jetten MSM, van Niftrik L, Reimann J, Op den Camp HJM (2019) Characterization of a novel cytochrome $\mathrm{c}_{\mathrm{GJ}}$ as the electron acceptor of XoxF-MDH in the thermoacidophilic methanotroph Methylacidiphilum fumariolicum SolV. Biochim Biophys Acta 1867:595-603. https://doi.org/10. 1016/j.bbapap.2019.04.001

Wu YW, Simmons BA, Singer SW (2016) MaxBin 2.0: an automated binning algorithm to recover genomes from multiple metagenomic datasets. Bioinformatics 32:605-607. https://doi.org/10.1093/bioinformatics/ btv638

Zuckerkandl E, Pauling L (1965) Molecules as documents of evolutionary history. J Theor Biol 8:357-366. https://doi. org/10.1016/0022-5193(65)90083-4

Publisher's Note Springer Nature remains neutral with regard to jurisdictional claims in published maps and institutional affiliations. 